Kenward, B, Hellmer, K, Soderstrom Winter, L and Eriksson, M

Four-year-olds' strategic allocation of resources: Attempts to elicit reciprocation correlate negatively with spontaneous helping.

Kenward, B, Hellmer, K, Soderstrom Winter, L and Eriksson, M (2015) Four-year-olds' strategic allocation of resources: Attempts to elicit reciprocation correlate negatively with spontaneous helping. Cognition, 136, pp. 1-8.

doi: 10.1016/j.cognition.2014.11.035

This version is available: https://radar.brookes.ac.uk/radar/items/f4fb80e9-ee02-4cbe-958c-adb4f612b661/1/

Available on RADAR: July 2016

Copyright $@$ and Moral Rights are retained by the author(s) and/ or other copyright owners. A copy can be downloaded for personal non-commercial research or study, without prior permission or charge. This item cannot be reproduced or quoted extensively from without first obtaining permission in writing from the copyright holder(s). The content must not be changed in any way or sold commercially in any format or medium without the formal permission of the copyright holders.

This document is the postprint version of the journal article. Some differences between the published version and this version may remain and you are advised to consult the published version if you wish to cite from it. 
Kenward et al.

\title{
Four-year-olds' strategic allocation of resources: attempts to elicit reciprocation correlate negatively with spontaneous helping
}

\author{
Ben Kenward*, Kahl Hellmer, Lina Söderström Winter, Malin Eriksson \\ Department of Psychology, Uppsala University, Box 1225, 75142 Uppsala, Sweden. \\ *Corresponding author. E-mail address: ben.kenward@wolfson.oxon.org. \\ Telephone: +46768 500221. No fax. \\ In press in Cognition (accepted 17.11.2014)
}

\begin{abstract}
Behaviour benefiting others (prosocial behaviour) can be motivated by self-interested strategic concerns as well as by genuine concern for others. Even in very young children such behaviour can be motivated by concern for others, but whether it can be strategically motivated by self-interest is currently less clear. Here, children had to distribute resources in a game in which a rich but not a poor recipient could reciprocate. From four years of age participants strategically favoured the rich recipient, but only when recipients had stated an intention to reciprocate. Six- and eight-year-olds distributed more equally. Children allocating strategically to the rich recipient were less likely to help when an adult needed assistance but was not in a position to immediately reciprocate, demonstrating consistent cross-task individual differences in the extent to which social behaviour is self- versus other-oriented even in early childhood. By four years of age children are capable of strategically allocating resources to others as a tool to advance their own self-interest.
\end{abstract}

25 Keywords: Prosocial behaviour; self-interested social behaviour; resource distribution;

26 helping; preschoolers 
Kenward et al.

\section{Introduction}

Humans display unusually high levels of behaviour benefitting even unrelated others, because others tend to reciprocate (Nowak \& Sigmund, 2005). This functional explanation does not, however, solve the question of the psychological mechanisms that cause such prosocial behaviour (de Waal, 2008). It can be motivated by strategic self-interested concerns such as expectations of reciprocation, but also by feelings of genuine sympathy, and debate continues as to the nature of the complex interplay between concerns for self and others (Stich, Doris, \& Roedder, 2010). The developmental perspective necessary to understand this interplay is missing, however, because although there is evidence that sympathetic concern motivates prosocial behaviour in very young children (Hepach, Vaish, \& Tomasello, 2013; Vaish, Carpenter, \& Tomasello, 2009; Warneken \& Tomasello, 2009), it is less clear whether self-interested strategic concerns can motivate their prosocial behaviour.

An investigation of strategic social behaviour in preschoolers would also be highly revealing because such behaviour requires advanced socio-cognitive problem solving abilities that are not otherwise clearly evident in children of this age (Green \& Rechis, 2006; Rubin \& Rose-Krasnor, 1992). An individual difference approach would also be valuable in this context because while clear individual differences in strategic social behaviour are seen in adults and school-age children (Jones \& Paulhus, 2009; Steinbeis, Bernhardt, \& Singer, 2012; Wilson, Near, \& Miller, 1996), nothing is known about these differences' earlier developmental roots. The current study fills these gaps.

Motivations for young children's prosocial behaviour are diverse (Paulus \& Moore, 2012). Apart from sympathy, other factors include socialization (Brownell, 2013; Brownell, Svetlova, Anderson, Nichols, \& Drummond, 2013), fairness concerns (Paulus \& Moore, 2012), and the desire to participate in the activities of others (Rheingold, 1982).

Furthermore, there are observations consistent with the hypothesis that preschoolers, like older children (Repacholi, Slaughter, Pritchard, \& Gibbs, 2003; Steinbeis et al., 2012), may engage in strategic prosociality. Specific patterns of prosocial and aggressive behaviour correlate with social dominance in a manner suggesting that preschoolers use prosocial behaviour to mitigate the negative consequences of aggression (Hawley, 2002; Hawley \& Geldhof, 2012; Roseth et al., 2011). When choosing how to share, preschoolers take into account factors that are of strategic importance, for example by sharing more with those who were themselves generous or worked hard or are friends (Kanngiesser \& Warneken, 2012; Paulus \& Moore, 2012). Audience effects are very suggestive: five-year-olds are more generous when they are observed (Engelmann, Herrmann, \& Tomasello, 2012; Leimgruber, Shaw, Santos, \& Olson, 2012). While such selective prosociality is clearly functionally strategic, it is not yet fully clear that it is psychologically motivated by strategic cognition such as concern for reputation or reciprocation. Such functional social behaviour can also be subserved by automatic mechanisms (Bargh, Schwader, Hailey, Dyer, \& Boothby, 2012) such as automatic tendencies to give more to those you like or to behave more prosocially when observed. Audience effects can be unconscious in adults (Haley \& Fessler, 2005; Nettle et al., 2013) and even cleaner fish cheat less when cleaning in the presence of bystander client fish (Pinto, Oates, Grutter, \& Bshary, 2011). 
Kenward et al.

Here we conduct an experiment in which strategic resource allocation is possible but can only arise from an explicitly strategic motivation. This is because participants must consider not only the presence or absence of others, but also their material ability to reciprocate (Experiments 1 and 2), and whether or not they state an intention to reciprocate (Experiment 2). Participants play a game with two experimenters. One round consists of each player in turn using a token (if they have one) to buy from a vending machine a plastic egg containing either one or two candies (ostensibly at random but in fact in a predetermined sequence). One candy is always kept, but an extra candy must be given to either of the other players (Fig. 1). If the hypothesis that children are able and motivated to engage in strategic resource allocation holds, then they are predicted to prefer to allocate candies to participants who have access to tokens and who have stated an intention to reciprocate. Experimenters' access to tokens is manipulated in experiments 1 and 2 and their stated intention to reciprocate is manipulated in experiment 2.

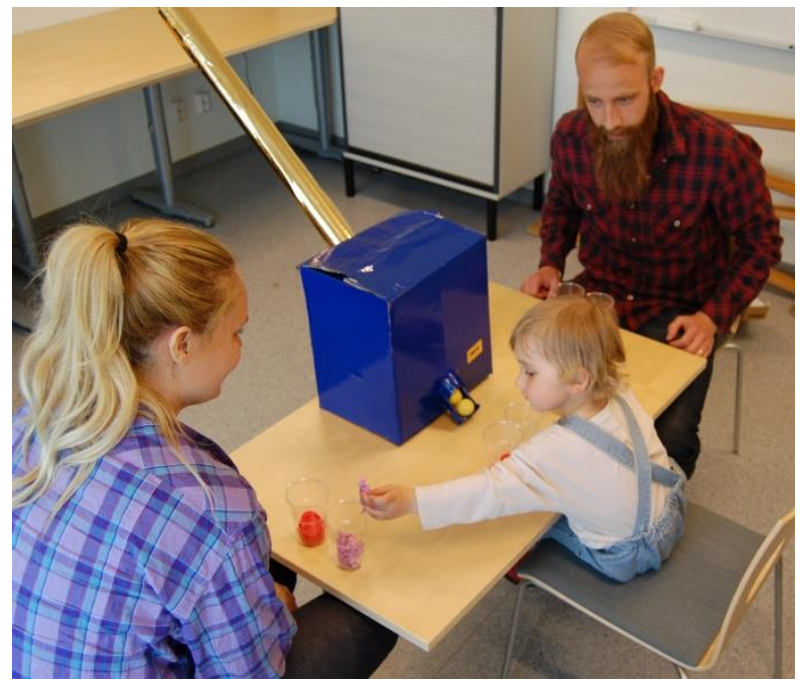

84 Fig. 1. A participant handing a candy to the token-rich experimenter.

We also examine whether there are consistent individual differences in the extent to which social behaviour is self- or other-oriented that produce individually consistent behaviour across different situations with the possibility for prosocial behaviour. Although such consistent individual differences have not previously been found in young children (Dunfield \& Kuhlmeier, 2010, 2013; Paulus, Kühn-Popp, Licata, Sodian, \& Meinhardt, 2013; Thompson \& Newton, 2013), their presence in older children and adults indicates that they might exist (Penner, Dovidio, Piliavin, \& Schroeder, 2005). Participants are tested for their tendency to spontaneously help an adult in need, a behaviour that has been argued to be motivated by concern for others (Hepach et al., 2013; Warneken \& Tomasello, 2009). We use a helping test in which there is little motive for strategic helping as reciprocation is unlikely to be forthcoming because the adult is not present when helped. If individuals consistently differ across tasks in the extent to which their choices concerning social behaviour are self- versus other-oriented, then helping in this situation is predicted to correlate negatively with strategic distribution in the sharing game. 
Kenward et al.

99

100

101

102

103

104

105

106

107

108

109

110

111

112

113

114

115

116

117

118

119

120

121

122

123

124

125

126

127

128

129

130

131

132

133

134

135

136

137

138

139

We test four-year-olds; the procedure would presumably be extremely challenging for younger children because of their limited understanding of others' verbally expressed intentions (Apperly \& Butterfill, 2009). We also test older children to explore the competing influences of different developmental processes: older children are able to be more strategic because of improved cognitive skills (Steinbeis et al., 2012), but might act less strategically because of increased commitment to fair distribution (Damon, 1994; Gummerum, Hanoch, \& Keller, 2008).

\section{Experiment 1}

\subsection{Method}

Fifty-two participants were clustered in three age-groups: 16 four-year-olds ( 7 girls, $M=50$ months, $S D=3$ ), 24 six-year-olds (11 girls, $M=80$ months, $S D=3$ ), and 12 eight-yearolds (5 girls, $M=98$ months, $S D=3$ ). Two additional six-year-olds were tested but excluded from analysis due to experimenter error. One four-year-old and two six-year-olds were included in analysis of the sharing game but excluded from analysis of spontaneous helping because of parental interference, likewise one six-year-old because of experimenter error.

Participants first observed the three-player sharing game. A model experimenter played two rounds with a token-rich and a token-poor experimenter, going first and sharing first with one then the other (counterbalanced), without justifying her choices. The rich and poor experimenters (identities counterbalanced) shared one candy each with the model, saying "I usually share with those who share with me, and [the model] shared with me, so I'm sharing with her". On the turn they were not shared with, the rich and poor experimenters obtained eggs with only one candy.

After the demonstration rounds the model left and the participant took her place (Fig. 1). The rich experimenter and the participant had many tokens left but the poor experimenter had now run out. Seven rounds were played, with the child always receiving an egg with two candies and therefore choosing who to share with, the rich experimenter receiving eggs with only one candy, and the poor experimenter saying that because she had no tokens she must skip her turn. The only exception was on turn four: the poor experimenter found a final token in her pocket, and to allay suspicions the game was rigged, both experimenters received an egg with two candies which they shared with the participant because "[the participant] shared with me". The procedure establishes that both experimenters intend to reciprocate, and that the rich experimenter is likely to be able to do so, without either experimenter actually reciprocating more often than the other. At turn four a minority of participants had not in fact shared with both experimenters, and it was therefore not always true that "[the participant] shared with me", but supplementary analyses in which trials after this event were excluded produced the same results, see Supplementary Online Material (SOM).

Participants might favour the rich experimenter for reasons other than strategy, preferring for example individuals who are lucky or control resources (Hawley, 2002; Olson, Banaji, Dweck, \& Spelke, 2006). To control for this participants were asked to leave their final 
Kenward et al.

140 token with either the rich or poor experimenter when it was time to go as they did not have

141 time to use it. Non-strategic reasons for preferring the rich individual, but not strategic

142 reasons, predict that the final token will also be allocated to the rich individual.

143 After the sharing game, participants were tested for their tendency to spontaneously help.

144 Immediately after the final round of the sharing game, the poor experimenter received a

145 telephone text-message that both experimenters must leave immediately. Hurrying to leave,

146 the poor experimenter knocked over the rich experimenter's cup of tokens, commenting

147 that she had no time to pick them up. Helping was scored if the participant began picking

148 up tokens in the $45 \mathrm{~s}$ before the experimenter returned. Further details of participants,

149 procedure and analysis are available as SOM.

\section{$150 \quad$ 2.2. Results}

151 Consistent with the hypothesis that children strategically choose to favour a rich individual

152 who has the potential to reciprocate, across ages participants allocated more candies to the

153 rich experimenter than the poor, $t(51)=2.19, p=.033, d=.30$ (Fig. 2). Candies allocated

154 to the rich experimenter was not clearly predicted by age, $t(45)=1.65, p=.106$

155 (generalized least squares model), unstandardized beta $=-.21,95 \%$ CI [-.47, .04]. Younger

156 participants did however show a greater deviation from equal division between the

157 experimenters, demonstrated by a negative correlation between age and the absolute

158 difference from 50:50 distribution, $F(1,50)=7.13, p=.010, R^{2}=.12$ (linear regression).

159 When leaving the experiment, $88 \%$ of participants gave their final token to the poor

160 experimenter, meaning they were less likely to favour the rich experimenter in the final

161 token allocation than they were to favour the rich experimenter with most candies in the

162 sharing game, $p<.001$ (McNemar test). Non-strategic explanations for favouring the rich

163 experimenter were therefore unlikely. 
Kenward et al.

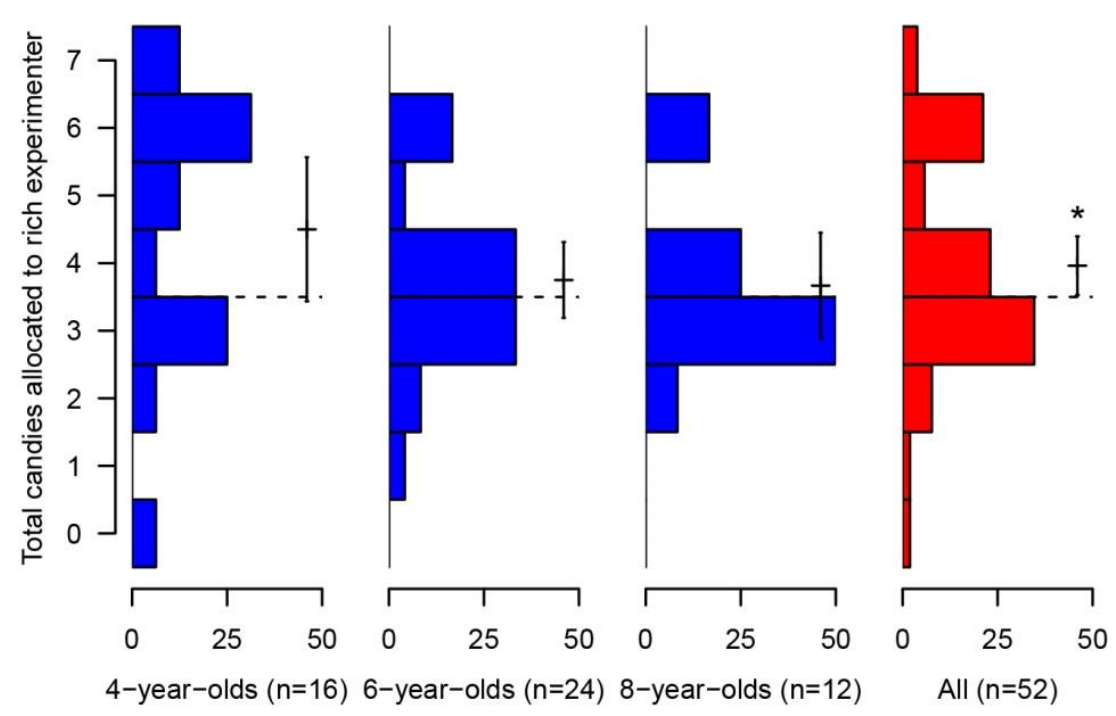

Fig. 2. Percentage frequency histograms of candies allocated to the rich experimenter in Experiment 1, with means and associated 95\% CI. The asterisk indicates significant deviation from equal distribution between the rich and poor experimenters $(p<.05)$.

We had hypothesised that children who are more likely to use resource allocation as a selfinterested strategic tool are less likely to help when immediate reciprocation is unlikely to be forthcoming. This predicts a negative correlation between helping and allocating to the rich experimenter, and indeed, controlling for age, participants who did not help had shared more candies with the rich experimenter, $t(45)=2.93, p=.005, d=.88$ (generalized least squares model, see SOM for details). Inclusion of the age * helping interaction in the model revealed no effect, $t(44)=.23, p=.820$, meaning there was no evidence that the relation between helping and allocating to the rich experimenter depended on age (Table 1). Helping did not depend on age, Wald $Z=1.38, p=.169$ (binary logistic regression, Table $1)$.

\section{Table 1.}

Participants who spontaneously helped allocated fewer candies to the rich experimenter irrespective of age.

\begin{tabular}{ccccc}
\hline & & \multicolumn{2}{c}{ Mean number of 7 candies allocated to rich experimenter } \\
\cline { 4 - 5 } Age & & $\begin{array}{c}\text { \% who } \\
\text { helped }\end{array}$ & Participants who helped & Participants who did not help \\
\hline 4 & 15 & 47 & 4.1 & 5.4 \\
6 & 21 & 67 & 3.4 & 4.3 \\
8 & 12 & 67 & 3.2 & 4.5 \\
\hline
\end{tabular}


Kenward et al.

\section{Experiment 2}

186 Experiment 2 was designed to test whether the results of Experiment 1 could be replicated in a group composed only of four-year-olds, and to include an improved control by varying the stated sharing intentions of the rich and poor experimenters. In the reciprocal condition, as in Experiment 1, the experimenters stated an intention to reciprocate. In the control condition, the rich and poor experimenters instead stated an intention to share with one another. In the control condition there could therefore be no incentive to strategically share with the rich experimenter, but other reasons to prefer the rich experimenter apply to both conditions. Our prediction was therefore that participants would favour the rich experimenter more in the reciprocal than the control condition. The two conditions are implemented both between and within subjects, with a condition switch half-way through the game. The between subjects comparison of distribution prior to the switch was most important. This was because within subject differences were expected to be weaker as children of this age find switching to cope with new circumstances challenging (Anderson \& Reidy, 2012; Zelazo, 2006) and also because for practical reasons the condition switch was demonstrated with fewer trials than the establishment of the first condition. The within subject aspect of the design was nevertheless included as an exploration of children's

202 potential ability to switch.

203

\subsection{Method}

Participants were 48 four-year-olds (21 girls, $M=48$ months, $S D=1$ ) randomly divided into two groups beginning in the reciprocal or control conditions. Three addition participants were tested but excluded from analysis, two due to parental or sibling interference and one due to an insufficient grasp of Swedish. Three participants were excluded only from analysis of spontaneous helping due to ambiguous behaviour (see below).

The reciprocal group procedure was the same as in Experiment 1, with minor changes including the addition of a third demonstration round (see SOM). Four test rounds were conducted in a first test phase. The control condition differed from the reciprocal condition only in that rather than sharing reciprocally with the model during the demonstration phase, the rich and poor experimenters shared with each other, saying "I usually share with my best friend, and [the other experimenter] is my best friend, so I'm sharing with her".

During the fourth round, after the participant's turn, the condition was switched. As in Experiment 1, both experimenters received an extra candy to share, but rather than sharing according to the intentions they stated during the demonstration phase, they both switched to sharing in the opposite way, explaining: "Now I have changed my mind about how I share. From now on I will..." either "... share with my best friend, and [the other experimenter] is my best friend, so I'm sharing with her" (switching from reciprocal to control) or "... share with those who share with me, and [the participant] shared with me, so I'm sharing with her" (switching from control to reciprocal). Four rounds were conducted in this second test-phase. At switching from control to reciprocal, a minority of participants 
Kenward et al.

225 were potentially confused because they had not in fact shared with both experimenters.

226 Supplementary analyses in which these participants were excluded did not alter the results

227 (see SOM). Coding of participants' potential protest at the experimenters' failure to share

228 with them when switching from the reciprocal condition was aborted after coding 10

229 participants because no verbal protest was observed, although negative facial expressions

230 were observed in 3 of these participants.

231 The spontaneous helping task was the same as in Experiment 1 but an addition was made to

232 the coding procedure to accommodate a new behaviour observed in three participants.

233 These participants (one in the reciprocal-condition-first group) picked up the tokens but

234 then later spontaneously attempted to or stated an intention to use them for themselves.

235 Because it was therefore ambiguous whether they were helping or planning theft when they

236 first picked up the tokens, they were excluded from analysis of helping. All participants

237 who picked up tokens and who did not attempt or state an intention to use them for

238 themselves had replaced the refilled token cup on the table and were therefore coded as

239 unambiguously helping.

240 3.2. Results

241 Our first-test-phase prediction that reciprocal condition participants would favour the rich

242 experimenter more than control condition participants was confirmed, $t(45)=2.29, p=$

$243.027, d=.66$ (Fig. 3). Furthermore, in the first-test-phase reciprocal condition participants

244 allocated more to the rich than poor experimenter, $t(23)=2.08, p=.049, d=.42$. One

245 participant, prior to allocating to the rich experimenter, said to the poor experimenter

246 “you've got no tokens so I'm not sharing with you".

247 Participants beginning in the reciprocal condition allocated less candies to the rich

248 experimenter after the switch, $t(23)=2.07, p=.050, d=.42$ (Fig. 3). Some children who

249 had anticipated reciprocation from the rich experimenter therefore stopped favouring the

250 rich experimenter after the expected reciprocation did not occur. Participants beginning in

251 the control condition did not change their distribution pattern at all between the phases,

252 allocating exactly the same number of candies to the rich experimenter both before and

253 after the switch (Fig. 3). 


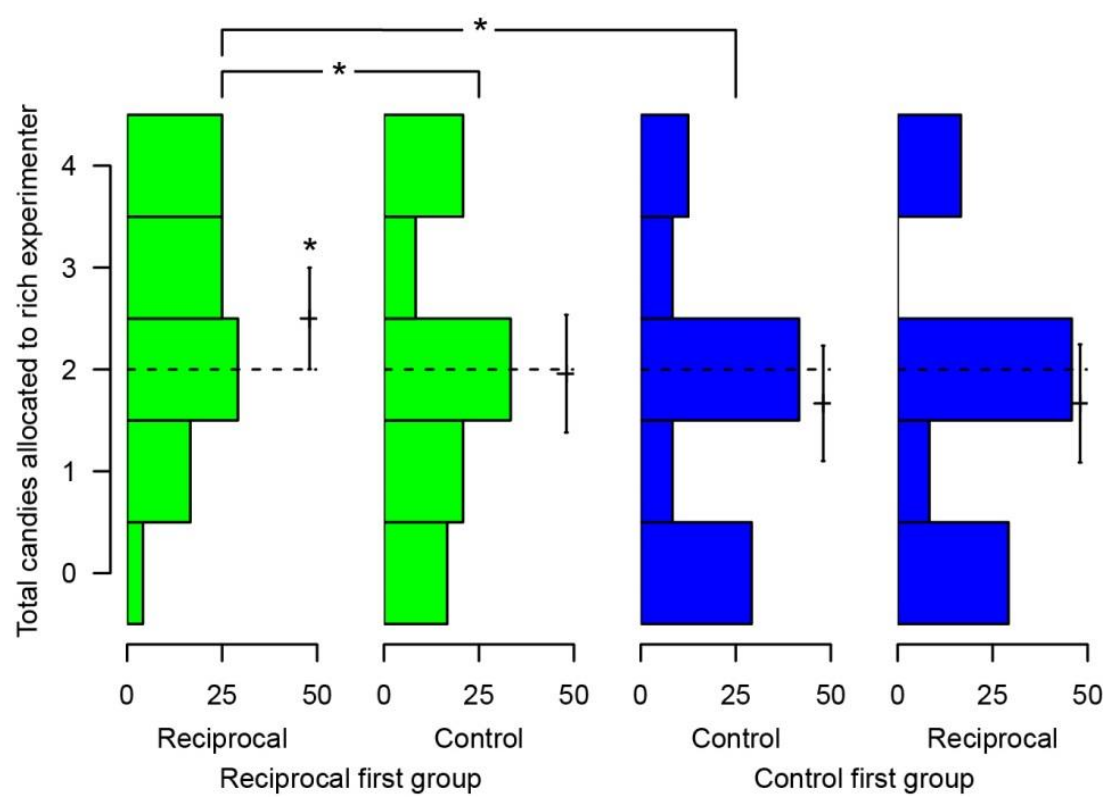

255 Fig. 3. Percentage frequency histograms of candies allocated to the rich experimenter in

256 Experiment 2, with means and associated 95\% CI. $n=24$ per group. Asterisks indicate 257 significant deviation from equal distribution between the rich and poor experimenters 258 within conditions, and significant between-condition comparisons $(p \leq .05)$.

Because there is no evidence for strategic allocation after the condition switch, we compare the tendency to spontaneously help with distribution in the first test-phase only. In the reciprocal condition, the prediction of a negative correlation between helping and allocating to the rich experimenter was again confirmed: the $40 \%$ of participants who did not help had allocated more candies to the rich experimenter than those who did help, $M_{\text {NotHelped }}=3.10$, $95 \%$ CI $[2.47,3.73] ; M_{\text {Helped }}=2.23,95 \%$ CI $[1.57,2.89] ; t(20)=2.12, p=.047, d=.88$. Participants who did not help had shown a very strong tendency to favour the rich experimenter, $t(9)=3.97, p=.003, d=1.26$. As expected, there was no such negative correlation between helping and allocating to the rich experimenter in the control condition, $M_{\text {NotHelped }}=1.70,95 \%$ CI $[.74,2.66] ; M_{\text {Helped }}=1.60,95 \%$ CI $[.76,2.44] ; t(17)=.18, p=$ $.861(50 \%$ of participants helped).

\section{General discussion}

272 In four- to eight-years-olds' resource allocation, favouring of an individual was contingent on the individual's ability to reciprocate (Experiments 1 and 2) and on the individual's intention to reciprocate (Experiment 2). Favouring of a rich individual ceased after the individual reneged on the intention to reciprocate (Experiment 2) and was negatively correlated with helping (Experiments 1 and 2). This converging evidence clearly indicates that targets for resource allocation were chosen strategically in children as young as four.

278 It is known that children as young as three or four are able to choose appropriate problem solving strategies for familiar social situations such as negotiating inclusion in group 
Kenward et al.

activities or resource access or by lying to avoid disapproval (Polak \& Harris, 1999; Webster-Stratton \& Lindsay, 1999; Ziv, 2013). Here it is further established that four-yearolds can spontaneously and strategically generate a novel strategy which maximises their gain in a novel social situation. Because there was no positive feedback for favouring the rich experimenter, participants must have created the strategy from scratch (or arrived at it by creative adaptation of known strategies) and then chosen to adopt the strategy because of 286 its expected results.

287 Models of social problem solving (Crick \& Dodge, 1994; Rubin \& Rose-Krasnor, 1992; Semrud-Clikeman, 2007) also include the ability to re-evaluate a chosen strategy following unexpected results. In Experiment 2 participants stopped favouring the rich experimenter following her failure to reciprocate (because of the condition switch) which indicates that four-year-olds are also capable of such re-evaluation. Having chosen to distribute strategically, participants changed to equal distribution when they learned the initial strategy could no longer succeed. Participants apparently no longer saw a reason to deviate from norms of equal distribution, but their change in distribution may also have reflected frustration at the rich experimenter.

In participants instead experiencing a switch from the control to reciprocal condition, no change in behaviour was observed. For practical reasons the procedure establishing the condition switch at phase 2 was briefer than the establishment of the condition at phase 1 . It makes sense that the brief switch procedure was sufficient to inform participants already expecting reciprocation that such reciprocation would not in fact be forthcoming, but not sufficient to establish the more novel concepts of reciprocation and the possibility of its exploitation. Adapting to this latter switch type is more demanding, and strategy switches are inherently demanding for children of this age (Anderson \& Reidy, 2012; Zelazo, 2006).

Whereas four-year-olds tended to favour the rich experimenter, only a minority of six- and eight-year-olds did so, with the majority distributing as equally as possible. The reduced tendency with age towards favouritism of either experimenter was statistically clear, and there was a marginal trend for older children to allocate less to the rich experimenter. Together these results suggest that older children may have been more concerned with equal distribution, a result which would be consistent with a range of previous findings concerning the development of attitudes towards distributive justice (Gummerum et al., 2008; Paulus \& Moore, 2012; Rochat et al., 2009). This development has been argued to arise from older children's increased understanding of normative principles of fairness (Damon, 1994). However, it has also been observed that three-year-olds and even infants have some understanding of fairness (Geraci \& Surian, 2011; Paulus \& Moore, 2012; Sloane, Baillargeon, \& Premack, 2012; Sommerville, Schmidt, Yun, \& Burns, 2013). Conversely, in older children distribution can be very strategic (Steinbeis et al., 2012) and the relative importance of different types of fairness principles applied can depend on context (Gummerum et al., 2008). Together with the current result that strategic behaviour is established early, these observations suggest that the transition with age towards more equal distribution may be motivated by strategic concerns regarding personal reputation (Engelmann, Over, Herrmann, \& Tomasello, 2013; Shaw, 2013) as much as by an increased commitment to the moral principle of fairness. 
Kenward et al.

There are some potential limitations to the generality of our results because they concerns children's behaviour in one particular laboratory task. Cues indicating the possibility of reciprocation were explicitly verbal, and participants were compelled to allocate a resource to one of two individuals. It is not clear from this result how much strategic sharing would be observed in circumstances in which giving is optional or the possibility of reciprocation is less obvious. We note, however, that previous studies in which children have chosen whether or not to behave prosocially and in which cues were less explicit have provided results that were suggestive, if not conclusive, of strategically motivated prosocial behaviour (Engelmann et al., 2012; Hawley, 2002; Leimgruber et al., 2012; Rochat et al., 2009; Roseth et al., 2011). Furthermore, one very recent study closely parallels the current study by demonstrating that five-year-old participants were more generous to a second party in the presence of a third-party observer if the observer would later have an opportunity to share with the participant (Engelmann et al., 2013). In contrast to here, that study demonstrates general reputation management rather than direct reciprocation elicitation: participants could not distribute to the observer, so they were concerned with appearing generous rather than with directly benefitting a potential reciprocator. Because distributing participants were nevertheless sensitive to observers' ability to subsequently share with them, however, the study provides independent confirmation of preschoolers' ability to strategically distribute resources, beyond a simple audience effect.

Because prosocial behaviour is potentially self- or other-oriented, the motivation for such behaviour inside and outside the laboratory is frequently ambiguous. The current study finds evidence for both types of motivation. Although distribution by the youngest children was frequently motivated by concern for self, evidence for other-orientation across all agegroups and in both experiments comes from comparison with the spontaneous helping task: those who were more likely to spontaneously help were less likely to evidence selforientation when allocating. Although alternative explanations for such a correlational result cannot be completely ruled out (for example, helpful individuals might be less able to think strategically) the most likely interpretation is that individuals expressed a comparatively higher or lower other-orientation in both tasks. This conclusion is interesting for several reasons. A number of previous studies have found no correlations between young children's different prosocial behaviours such as instrumental helping, comforting, and generosity, and have found evidence for separate neural substrates, indicating that separate motivations underlie these different forms (Dunfield \& Kuhlmeier, 2010, 2013; Paulus et al., 2013; Thompson \& Newton, 2013). The current result indicates that there is in fact in preschoolers a degree of overlap in the motivation of different behaviours which benefit others in different ways, in that resource distribution and instrumental helping were both affected by a general other-orientation.

The current result is also of interest because although some have argued that young children's instrumental help is genuinely based on concern for others (Warneken \& Tomasello, 2009), others have argued that alternative explanations are similarly plausible (Paulus \& Moore, 2012). The correlation of instrumental helping with a reduced tendency to deviate from fair treatment of others for self-interested reasons indicates that concern for others does sometimes play a role in four-year-olds' instrumental helping. 
Kenward et al.

Although the existence of individual differences in general self- versus other-orientation has received little support from previous studies of preschoolers, studies of adults and older children have provided some evidence for stable cross-situation individual differences in prosocial behaviour (Penner et al., 2005). Furthermore, stability in prosocial behaviour has been found through early childhood (Kienbaum, 2014) and a modest degree of stability from childhood into adulthood (Eisenberg et al., 2002; Nantel-Vivier et al., 2009). Associations have been found between sympathy, moral cognition, and other-oriented behaviour, even in six-year-olds (Malti, Gummerum, Keller, \& Buchmann, 2009), lending further plausibility to the current finding. One study found individual consistency in oneyear-olds' behaviour across different resource distribution tasks (Sommerville et al., 2013).

It is important to note, however, that individual differences in general other-orientation do not imply that clear correlations will be found across all relevant tasks, because situationspecific individual differences and cognitive constraints may be stronger (as is evident from previous work on preschoolers). Here, we note that although favouring of the rich experimenter correlated with a lack of helping in the reciprocal condition, there was no correlation in the control condition. Although the control condition offered no incentive to strategically favour the rich experimenter, individuals who are more other-oriented and who therefore help more might have been expected to be more likely to compensate the poor experimenter by favouring them. In general, however, there was no evidence for systematic favouring of the poor experimenter. This is consistent with previous results showing that children during the primary school years gradually transition from emphasising equal distribution irrespective of context towards also taking prior individual needs into account (Frederickson \& Simmonds, 2008; Sigelman \& Waitzman, 1991). The current data supports the view that the tendency to deviate from fair distribution to help the needy develops after the preschool years, even in comparatively other-oriented individuals.

The negative relation between strategic distribution and helping did not depend on age, and indeed a reduced tendency to spontaneous help among those showing a greater tendency to strategic prosociality is also seen in adults (Wilson et al., 1996). In adults, manipulative prosocial behaviour does not correlate with intelligence or empathy (Jones \& Paulhus, 2009; Wilson et al., 1996), implying individual differences in strategic prosociality are primarily due to motivation rather than ability. The sources of the differences identified here are uncertain. We note that environmental factors contribute to some differences in very young children's prosocial behaviour (Brownell, 2013; Brownell et al., 2013). There are also genetic determinants of prosocial behaviour in adults and children (Ebstein, Knafo, Mankuta, Chew, \& Lai, 2012; Lewis \& Bates, 2011), and even indications of a genetic component to strategic prosocial behaviour in adults (Jones \& Paulhus, 2009; Wilson et al., 1996).

Evolutionary models indicate that highly self-interested human social behaviour is only successful at a low population-frequency (Mealey, 1995). In the light of this, it is noteworthy that self-interested strategic resource distribution was quite infrequent here in the older children. The sources of the different motives for seemingly altruistic behaviour in humans is a fascinating question which is only beginning to be resolved and which requires a continuation of this developmental individual-differences approach. 
Kenward et al.

\section{Acknowledgements}

410 Thanks to Kerstin Edvardsson and Karolina Hjort for data collection. This work was

411 supported by the by the Swedish Research Council (Vetenskapsrådet) grant 241-2011-1785

412 and the European Research Council grant StGCACTUS-312292.

\section{References}

414 Anderson, P. J., \& Reidy, N. (2012). Assessing executive function in preschoolers.

415 Neuropsychology Review, 22(4), 345-360. doi: 10.1007/s11065-012-9220-3

416 Apperly, I. A., \& Butterfill, S. A. (2009). Do humans have two systems to track beliefs and belief-

417 like states? Psychological Review, 116(4), 953-970. doi: 10.1037/a0016923

418 Bargh, J. A., Schwader, K. L., Hailey, S. E., Dyer, R. L., \& Boothby, E. J. (2012). Automaticity in social-cognitive processes. Trends in Cognitive Sciences, 16(12), 593-605. doi: 10.1016/j.tics.2012.10.002

Brownell, C. A. (2013). Early development of prosocial behavior: Current perspectives. Infancy, 18(1), 1-9. doi: 10.1111/infa.12004

Brownell, C. A., Svetlova, M., Anderson, R., Nichols, S. R., \& Drummond, J. (2013). Socialization of Early Prosocial Behavior: Parents' Talk About Emotions is Associated With Sharing and Helping in Toddlers. Infancy, 18(1), 91-119. doi: 10.1111/j.1532-7078.2012.00125.x

Crick, N. R., \& Dodge, K. A. (1994). A review and reformulation of social information-processing mechanisms in children's social adjustment. Psychological Bulletin, 115(1), 74-101. doi: 10.1037/0033-2909.115.1.74

429 Damon, W. (1994). Fair distribution and sharing: The development of positive justice. In B. Puka 430 (Ed.), Fundamental research in moral development (pp. 189-254). New York: Garland.

431 de Waal, F. B. M. (2008). Putting the altruism back into altruism: The evolution of empathy. 432 Annual review of psychology, 59, 279-300. doi: 10.1146/annurev.psych.59.103006.093625

433 Dunfield, K. A., \& Kuhlmeier, V. A. (2010). Intention-mediated selective helping in infancy. 434 Psychological Science, 21(4), 523-527.

435 Dunfield, K. A., \& Kuhlmeier, V. A. (2013). Classifying Prosocial Behavior: Children's Responses 436 to Instrumental Need, Emotional Distress, and Material Desire. Child Development, 84(5), 1766-

437 1776. doi: 10.1111/cdev.12075

438 Ebstein, R. P., Knafo, A., Mankuta, D., Chew, S. H., \& Lai, P. S. (2012). The contributions of 439 oxytocin and vasopressin pathway genes to human behavior. Hormones and Behavior, 61(3), 359440 379. doi: 10.1016/j.yhbeh.2011.12.014

441 Eisenberg, N., Guthrie, I. K., Cumberland, A., Murphy, B. C., Shepard, S. A., Zhou, Q., \& Carlo, G. 442 (2002). Prosocial development in early adulthood: A longitudinal study. Journal of Personality and 443 Social Psychology, 82(6), 993-1006. doi: 10.1037//0022-3514.82.6.993

444 Engelmann, J. M., Herrmann, E., \& Tomasello, M. (2012). Five-year olds, but not chimpanzees, 445 attempt to manage their reputations. Plos One, 7(10), e48433. doi: 10.1371/journal.pone.0048433

446 Engelmann, J. M., Over, H., Herrmann, E., \& Tomasello, M. (2013). Young children care more 447 about their reputation with ingroup members and potential reciprocators. Developmental Science, 448 16(6), 952-958. doi: 10.1111/desc.12086 
Kenward et al.

449

450

451

452

453

454

455

456

457

458

459

460

461

462

463

464

465

466

467

468

469

470

471

472

473

474

475

476

477

478

479

480

481

482

483

484

485

486

487

488

489

Frederickson, N. L., \& Simmonds, E. A. (2008). Special Needs, Relationship Type and Distributive Justice Norms in Early and Later Years of Middle Childhood. Social Development, 17(4), 10561073. doi: 10.1111/j.1467-9507.2008.00477.x

Geraci, A., \& Surian, L. (2011). The developmental roots of fairness: infants' reactions to equal and unequal distributions of resources. Developmental Science, 14(5), 1012-1020. doi: 10.1111/j.14677687.2011.01048.x

Green, V. A., \& Rechis, R. (2006). Children's cooperative and competitive interactions in limited resource situations: A literature review. Journal of Applied Developmental Psychology, 27(1), 4259.

Gummerum, M., Hanoch, Y., \& Keller, M. (2008). When child development meets economic game theory: An interdisciplinary approach to investigating social development. Human Development, 51(4), 235-261.

Haley, K. J., \& Fessler, D. M. T. (2005). Nobody's watching? Subtle cues affect generosity in an anonymous economic game. Evolution and Human Behavior, 26(3), 245-256. doi: 10.1016/j.evolhumbehav.2005.01.002

Hawley, P. H. (2002). Social dominance and prosocial and coercive strategies of resource control in preschoolers. International Journal of Behavioral Development, 26(2), 167-176. doi: $10.1080 / 01650250042000726$

Hawley, P. H., \& Geldhof, G. J. (2012). Preschoolers' social dominance, moral cognition, and moral behavior: An evolutionary perspective. Journal of Experimental Child Psychology, 112(1), 18-35. doi: 10.1016/j.jecp.2011.10.004

Hepach, R., Vaish, A., \& Tomasello, M. (2013). A new look at children's prosocial motivation. Infancy, 18(1), 67-90. doi: 10.1111/j.1532-7078.2012.00130.x

Jones, D. N., \& Paulhus, D. L. (2009). Machiavellianism. In M. R. Leary \& R. H. Hoyle (Eds.), Handbook of Individual Differences in Social Behavior (pp. 93-108). New York: Guilford.

Kanngiesser, P., \& Warneken, F. (2012). Young children consider merit when sharing resources with others. Plos One, 7(8), e43979. doi: 10.1371/journal.pone.0043979

Kienbaum, J. (2014). The development of sympathy from five to seven years: increase, decline or stability? A longitudinal study. Frontiers in Psychology, 5. doi: 10.3389/fpsyg.2014.00468

Leimgruber, K. L., Shaw, A., Santos, L. R., \& Olson, K. R. (2012). Young children are more generous when others are aware of their actions. Plos One, 7(10), e48292. doi:

10.1371/journal.pone.0048292

Lewis, G. J., \& Bates, T. C. (2011). A common heritable factor influences prosocial obligations across multiple domains. Biology Letters, 7(4), 567-570. doi: 10.1098/rsbl.2010.1187

Malti, T., Gummerum, M., Keller, M., \& Buchmann, M. (2009). Children's Moral Motivation, Sympathy, and Prosocial Behavior. Child Development, 80(2), 442-460. doi: 10.1111/j.14678624.2009.01271.x

Mealey, L. (1995). The sociobiology of sociopathy: An integrated evolutionary model. Behavioral and Brain Sciences, 18(Special Issue 03), 523-541. doi: doi:10.1017/S0140525X00039595

Nantel-Vivier, A., Kokko, K., Caprara, G. V., Pastorelli, C., Gerbino, M. G., Paciello, M., . . . Tremblay, R. E. (2009). Prosocial development from childhood to adolescence: a multi-informant 
Kenward et al.

490 perspective with Canadian and Italian longitudinal studies. Journal of Child Psychology and

491 Psychiatry, 50(5), 590-598. doi: 10.1111/j.1469-7610.2008.02039.x

492 Nettle, D., Harper, Z., Kidson, A., Stone, R., Penton-Voak, I. S., \& Bateson, M. (2013). The 493 watching eyes effect in the Dictator Game: it's not how much you give, it's being seen to give 494 something. Evolution and Human Behavior, 34(1), 35-40. doi:

495 10.1016/j.evolhumbehav.2012.08.004

496 Nowak, M. A., \& Sigmund, K. (2005). Evolution of indirect reciprocity. Nature, 437(7063), 12914971298.

498 Olson, K. R., Banaji, M. R., Dweck, C. S., \& Spelke, E. S. (2006). Children's biased evaluations of 499 lucky versus unlucky people and their social groups. Psychological Science, 17(10), 845-846. doi:

$500 \quad 10.1111 / \mathrm{j} .1467-9280.2006 .01792 . x$

501 Paulus, M., Kühn-Popp, N., Licata, M., Sodian, B., \& Meinhardt, J. (2013). Neural correlates of 502 prosocial behavior in infancy: Different neurophysiological mechanisms support the emergence of 503 helping and comforting. Neuroimage, 66(0), 522-530. doi:

504 http://dx.doi.org/10.1016/j.neuroimage.2012.10.041

505 Paulus, M., \& Moore, C. (2012). Producing and understanding prosocial actions in early childhood. 506 Advances in child development and behavior, 42, 271-305.

507 Penner, L. A., Dovidio, J. F., Piliavin, J. A., \& Schroeder, D. A. (2005). Prosocial Behavior:

508 Multilevel Perspectives. Annual review of psychology, 56(1), 365-392. doi:

509 doi:10.1146/annurev.psych.56.091103.070141

510 Pinto, A., Oates, J., Grutter, A., \& Bshary, R. (2011). Cleaner wrasses Labroides dimidiatus are

511 more cooperative in the presence of an audience. Current Biology, 21(13), 1140-1144. doi:

$512 \quad 10.1016 /$ j.cub.2011.05.021

513 Polak, A., \& Harris, P. L. (1999). Deception by young children following noncompliance.

514 Developmental Psychology, 35(2), 561-568. doi: 10.1037//0012-1649.35.2.561

515 Repacholi, B., Slaughter, V., Pritchard, M., \& Gibbs, V. (2003). Theory of mind, Machiavellianism, 516 and social functioning in childhood. In B. Repacholi \& V. Slaughter (Eds.), Individual differences 517 in theory of mind (pp. 67-98). Hove, UK: Psychology Press.

518 Rheingold, H. L. (1982). Little children's participation in the work of adults, a nascent prosocial 519 behavior. Child Development, 53(1), 114-125.

520 Rochat, P., Dias, M. D. G., Guo, L. P., Broesch, T., Passos-Ferreira, C., Winning, A., \& Berg, B. 521 (2009). Fairness in distributive justice by 3 -and 5-year-olds across seven cultures. Journal of Cross522 Cultural Psychology, 40(3), 416-442. doi: 10.1177/0022022109332844

523 Roseth, C. J., Pellegrini, A. D., Dupuis, D. N., Bohn, C. M., Hickey, M. C., Hilk, C. L., \& Peshkam, 524 A. (2011). Preschoolers' bistrategic resource control, reconciliation, and peer regard. Social 525 Development, 20(1), 185-211. doi: 10.1111/j.1467-9507.2010.00579.x

526 Rubin, K. H., \& Rose-Krasnor, L. (1992). Interpersonal problem solving and social competence in 527 children. In V. B. V. Hasselt \& M. Hersen (Eds.), Handbook of Social Development: A Lifespan 528 Perspective (pp. 283-323). New York: Plenum Press.

529 Semrud-Clikeman, M. (2007). Social Competence in Children. New York: Springer. 
Kenward et al.

530 Shaw, A. (2013). Beyond "to Share or Not to Share": The Impartiality Account of Fairness. Current

531 Directions in Psychological Science, 22(5), 413-417. doi: 10.1177/0963721413484467

532 Sigelman, C. K., \& Waitzman, K. A. (1991). The development of distributive justice orientations -

533 contextual influences on childrens resource allocations. Child Development, 62(6), 1367-1378.

534 Sloane, S., Baillargeon, R., \& Premack, D. (2012). Do infants have a sense of fairness?

535 Psychological Science, 23(2), 196-204. doi: 10.1177/0956797611422072

536 Sommerville, J. A., Schmidt, M. F. H., Yun, J.-e., \& Burns, M. (2013). The Development of

537 Fairness Expectations and Prosocial Behavior in the Second Year of Life. Infancy, 18(1), 40-66.

538 doi: 10.1111/j.1532-7078.2012.00129.x

539 Steinbeis, N., Bernhardt, B. C., \& Singer, T. (2012). Impulse control and underlying functions of

540 the left DLPFC mediate age-related and age-independent individual differences in strategic social

541 behavior. Neuron, 73(5), 1040-1051. doi: 10.1016/j.neuron.2011.12.027

542 Stich, S., Doris, J. M., \& Roedder, E. (2010). Altruism. In J. M. Doris (Ed.), The Moral Psychology

543 Handbook. Oxford: Oxford University Press.

544 Thompson, R. A., \& Newton, E. K. (2013). Baby altruists? Examining the complexity of prosocial

545 motivation in young children. Infancy, 18(1), 120-133. doi: 10.1111/j.1532-7078.2012.00139.x

546 Vaish, A., Carpenter, M., \& Tomasello, M. (2009). Sympathy through affective perspective taking

547 and its relation to prosocial behavior in toddlers. Developmental Psychology, 45(2), 534-543.

548 Warneken, F., \& Tomasello, M. (2009). The roots of human altruism. British Journal of

549 Psychology, 100, 455-471.

550 Webster-Stratton, C., \& Lindsay, D. W. (1999). Social competence and conduct problems in young 551 children: issues in assessment. Journal of Clinical Child Psychology, 28(1), 25-43. doi:

552 10.1207/s15374424jccp2801_3

553 Wilson, D. S., Near, D., \& Miller, R. R. (1996). Machiavellianism: A synthesis of the evolutionary

554 and psychological literatures. Psychological Bulletin, 119(2), 285-299. doi: 10.1037/0033-

$555 \quad 2909.119 .2 .285$

556 Zelazo, P. D. (2006). The Dimensional Change Card Sort (DCCS): a method of assessing executive 557 function in children. Nature Protocols, 1(1), 297-301. doi: 10.1038/nprot.2006.46

558 Ziv, Y. (2013). Social information processing patterns, social skills, and school readiness in 559 preschool children. Journal of Experimental Child Psychology, 114(2), 306-320. doi:

560 http://dx.doi.org/10.1016/j.jecp.2012.08.009 